\title{
A Typology of Digital Offerings
}

\author{
Katrine Folkmann \\ Department of Digitalization \\ Copenhagen Business School \\ Copenhagen, Denmark \\ krf.digi@cbs.com
}

\author{
Jonas Hedman \\ Department of Digitalization \\ Copenhagen Business School \\ Copenhagen, Denmark \\ jhe.digi@cbs.dk
}

\author{
Michel Avital \\ Department of Digitalization \\ Copenhagen Business School \\ Copenhagen, Denmark \\ michel@avital.net
}

\begin{abstract}
This paper develops a typology of digital offerings to shed light on the distinct characteristics of this emerging digital phenomenon. Drawing on Roman contract law, the typology focuses on digital rights offered (selling, leasing, partnering, and agencing) and digital assets involved (tangible and intangible). These two dimensions lead to eight archetypes that we illustrate through the diverse Amazon portfolio of digital offerings. The typology sets out to shape the scholarly discourse around digital offering research and practice and to provide a foundation from which the characteristics and mechanisms of digital offering value appropriation can be further understood and operationalized. Ultimately, by rejecting the traditional service vs. product distinction and instead accounting for offering variations based on the intrinsic merits of digital offerings, we are embracing a digital terminology rather than attempting to transfer the terminology of the physical world to the digital realm.
\end{abstract}

\section{Introduction}

Digital offerings, such as personal computers, phones, software, streamed media, and cloud storage, are omnipresent in business-to-consumer, business-tobusiness, and business-to-government contexts. Amazon (our illustrative case example) provides digital offerings for all of these contexts, including Amazon Kindle e-reader (B2C), Amazon Open Service Broker API (B2B), and Amazon Web Services Cloud (B2G).

Digital offerings are data-enriched products and services that have the inherent capability to be integrated into a digital ecosystem and to provide a personalized user experience. In practice, digital offerings constitute the interaction point between the seller (frequently referred to as the 'developer') and the buyer (frequently referred to as the 'user') [1], where the buyer confers legal rights to the buyer upon the completion of the exchange (under the principles of contract law). This paper focuses on the digital outputs (digital offerings) exchanged bi-directionally between sellers and buyers (transfer of rights to buyers in return for payment).

Research on digitalization and information technology tends to focus on the behavior of the buyer or the design of the digital offering. This research focus has provided in-depth knowledge of the design of digital offerings. However, in order to gain a deeper understanding of the value appropriation mechanisms of digital offerings, we need a better grasp of the interaction between sellers and buyers. Consequently, we need to pay more attention to the digital output exchanged between sellers and buyers, as well as how the different types of asset rights are involved in the process of transferring the ownership of digital offering asset types.

While digital offerings have long been known to grow faster than traditional product and service mixes [2], the COVID-19-induced customer surge toward online channels has propelled companies to take quantum leaps in creating and refocusing their digital offerings. Consequently, the notion of a 'digitaloffering-intensive' industrial sector is more likely to depict emerging business than the conventional notion of offerings, which has dominated the discourse over the last three decades of neo-industrialism [3]. Consequently, the prevailing digital transformation of socio-technical systems requires an update of business theory, which necessitates a concomitant upgrade of the offering dimensions in accordance with digital reality. However, as reflected in the extant literature [4], the radical changes in the nature of business resulting from the digital transformation has seemingly not been fully reflected in the theoretical 
landscape, thereby leaving a void of theory on digital offerings.

Adhering to the adage that "nothing is as practical as a good theory" [5], the void of coherent theory on digital offerings undermines the development of professional practices through the accumulation of knowledge in a systematic manner [6]. Specifically, the theoretical offering void is problematic for two reasons: (1) offerings are rapidly transforming into, or being born, digital offerings, for which we lack a fundamental theoretical basis, and (2) the properties of digital offerings differ from those of conventional offerings, and thus we need a consistent theory for digital offerings.

This paper attempts to mitigate this shortcoming of prior work by broadening the scope of Information Systems (IS) research in terms of value appropriation through a typology of for-profit digital offerings that is grounded in Roman contract law. Furthermore, instead of accounting for offering variations through a continuum that stems from the dichotomy between products and services [7], the 'typology of digital offerings' aims to categorize mutually exclusive offering archetypes based on the intrinsic merits of digital offerings. In other words, we embrace digital terminology and categorization rather than attempting to transfer the terminology of the physical world to the digital realm.

The following section reviews the literature on digital offerings and outlines a temporal progression of studied offering forms and the core foci of the digital offering literature. We then present Roman contract law and our conceptual typology of digital offerings by explicitly highlighting the two dimensions of (1) digital rights offered and (2) digital assets involved. The remainder of the paper is devoted to discussing different perspectives on how the typology of digital offerings broadens the scope of IS research.

\section{Theoretical Foundation}

\subsection{Temporal Progression of Offering Forms}

A review of the extant literature reveals a threepronged temporal progression of studies on offerings. The first period stretched from the beginning of the $19^{\text {th }}$ century until the late 70 s and treated products and services as two independent categories. The second period started in the late $70 \mathrm{~s}$ along with the introduction of the offering concept [8], while a more comprehensive conceptualization only emerged a decade later [3] and changed the focus towards mixes of products and services [3]. Specifically, the offering concept constituted an alternative to a 'theory of the firm'. It emphasized a freeing of the mind from the product vs. service distinction, which gradually became less relevant from the early 80 s onward. The underlying logic was that all products require some degree of service to be of value, and services generally involve some form of product or artifact [9]. In the third period, which emerged in recent years, offerings are increasingly viewed through a digital lens and considered IT artifact instances [10] of digital productservice mixes.

Each of the three identified offering forms are associated with different value conceptualization types and anchored in separate theoretical paradigms. The unique perspective embedded in the concept of digital offerings, and their rooting in digital ecosystems, is attributed to the fact that they cannot be characterized through a value-in-exchange conceptualization because the customer's actions during usage are involved. Likewise, digital offerings cannot be described through a value-in-use conceptualization, because the service provider's activities are involved [11]. Instead, within digital ecosystems where value is interacted and co-created [12], value creation becomes a dialogical process [13][14] of value-in-interactions [15].

Consequently, whereas the first offering phase saw the company serve as a value provider, and the second offering phase saw customers serve as coproducers of their own value-producing activity, the third and current offering phase sees the company serve as an influencer and co-creator of a customer value co-production. In other words, the temporal progression of offering value conceptualizations has changed from (1) output of a manufacturing process or value-chain logic towards (2) input to a value-creating process and, finally, (3) a dialogical process of direct interaction.

\subsection{Streams of Digital Offering Literature}

We reviewed the literature with a particular attention to developing the typology of digital offerings, rather than reiterating earlier reviews on topics that dominate the digital offering literature (e.g., technology, social media communication strategies, consumer behavior in a digital environment, and the pricing of digital offerings) [16] [7]. Subsequently, three dominant foci pertaining to digital offerings have emerged: value proposition, solutions offering, and bundled offering, as described below and in Figure 1.

First, the focus on value propositions in the context of digital offerings was initiated by strategy consultants seeking to explain, typically in a few key sentences, why customers should purchase the firm's goods and services [17]. The value proposition 
concept was popularized as a business model component in the late 90s [18] and later viewed as a co-created [19] and reciprocal construction of shared statement concerning the espoused value of a venture [20].

Second, the notion of digital solution offerings builds upon the early conceptualization of system selling [21]. The corresponding literature predominantly depicts and defines a solution as a constellation of products, services, and software that can solve customer-specific problems and that are relatively broad and complex, focused not only on technical integration but also on the entire usage context [22]. Specifically, offerings that are inherently enabled by information and communication technologies, are viewed as information-enriched solutions [1], which are continuously in the making through post-launch continuous digital innovation [23], and that come together in the form of solutions for consumers [24]. While being composed of binary code does not necessarily make digital offerings completely different from physical offerings, there are important distinctions relating to their material properties, which are (at least in theory) recombinable, editable, and distributable [25][26][27], thereby allowing them to evolve over time and inject generativity into the market offerings [28].

Third, the notion of bundling emerged in the context of 'digital offerings' [8] and further conceptualized [3] as product-service information mixes [8, p. 112] until being digitally reconceptualized in the sense of an IT artifact [10]. Specifically, offerings that are perpetually embodied in information and communication technologies constitute a growing area of research, commonly referred to as cyberphysical systems [29] or Digitized Interactive Platforms [12]. Specifically, these forms of bundled offerings relate to evolving digitalized networked arrangements of artifacts, persons, processes, and interfaces [12], as well as a means for the dynamic creation of experience value through ongoing and new types of networked interactions [30].

While we observe a growing interest in digital offerings - especially in the domains of marketing, management, and IS - a review of the extant literature clearly indicates an apparent concentration of publications in the business-model-associated category of value propositions. In essence, the extant literature implies that the dominant conceptualizations of digital offering remain rooted in the 80 s pre-digital value paradigms, which treat digital offerings as an interplay between Value-in-Exchange (market value) and Value-in-Use (phenomenological value). Thereby, the Value-in-Interactions (relational value) that characterizes today's digital reality appears underrepresented in the digital offering discourse.

Building on the three dominant foci of the digital offering literature (Fig. 1) and their differing views on digital offerings, we offer the following unifying working definition of digital offerings to underlie the development of the typology of digital offerings. Thus, we define digital offerings as data-enriched products and services that have the inherent capability to be integrated into a digital ecosystem and to provide a personalized user experience.

\begin{tabular}{|c|c|c|}
\hline \multicolumn{3}{|c|}{ DIGITAL OFFERING } \\
\hline$\nabla$ & 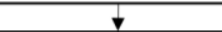 & $\nabla$ \\
\hline Value Proposition & Solutions Offering & Bundled Offering \\
\hline $\begin{array}{c}\text { Lusch \& Vargo, } \\
2006 \\
\text { Co-created } \\
\text { value } \\
\text { proposition }\end{array}$ & $-\begin{array}{c}\text { Ross et al., } 2019 \\
\text { Information- } \\
\text { enriched } \\
\text { solution }\end{array}$ & $\rightarrow \begin{array}{c}\text { Ramaswamy \& } \\
\text { Ozcan, } 2018 \\
\text { Digitalized } \\
\text { interactive } \\
\text { platform }\end{array}$ \\
\hline $\begin{array}{l}\text { Zott et al., } 2011 \\
\text { Business model } \\
\text { component }\end{array}$ & $\begin{array}{c}\text { Micken et al., } \\
2019 \\
\text { Product-service } \\
\text { continuum }\end{array}$ & $\mapsto \begin{array}{c}\text { Tuunanen, } 2019 \\
\text { Cyber-physical } \\
\text { system }\end{array}$ \\
\hline $\begin{array}{l}\text { Truong et al., } \\
2012\end{array}$ & $\begin{array}{c}\text { Lehmann \& } \\
\text { Recker, } 2019\end{array}$ & $\begin{array}{c}\text { Ramaswamy, } \\
2020\end{array}$ \\
\hline $\begin{array}{c}\text { Reciprocal } \\
\text { co-created value } \\
\text { proposition }\end{array}$ & $\begin{array}{l}\text { Ever-in-the- } \\
\text { making }\end{array}$ & $\begin{array}{l}\text { Networked } \\
\text { interaction }\end{array}$ \\
\hline
\end{tabular}

Figure 1: Digital offering literature

Taxonomy development is well-recognized in the IS literature [31], and classification research related to digital offerings is found within data-driven digital services [32] and content-based digital products [33]. The literature explores variations in digital offerings [7], but no explicit typologies or taxonomies specific to digital offerings could be identified.

\section{Roman Contract Law}

\subsection{The Source of Modern Contract Law}

We developed the typology of digital offering archetypes building on the source of modern contract law, namely the Roman law of 'things,' which furnishes the foundations of the majority of currentday business arrangements. This choice is based on a two-pronged motivation, as described below.

First, as the geographical reach and functional scope of contract law have gradually expanded over the course of several thousand years, part of the original wisdom appears to have been distorted, or, at the very least, buried in repeated layers of complexity. Therefore, if we are to really understand the value 
appropriation of digital offerings, it is necessary to go back to the original wisdom of Roman contract law.

Secondly, it is necessary to demonstrate the transactional explicitness of digital offerings in order to provide a foundation from which the characteristics and mechanisms of digital offerings can be further understood and operationalized. Furthermore, by going to the source of modern contract law, we can illustrate that digital offerings are dealing with fundamental transactional issues, which have been relevant since antiquity. As such, we build on the Roman foundation of contract law to illustrate that the merits of the transactional pattern of offerings have not changed substantially. Instead, the foundational categorization allows us to focus on the physical contractual element of rights transferring into the digital domain.

The strength of Roman law relates to how the Romans made law a thoroughly scientific subject by elaborately articulating a system of principles abstracted from the detailed concepts that constitute raw materials.

\subsection{Consensual Contracts and the Law of Things}

The Twelve Tables (Duodecim Tabulae) was a set of laws relating to value-creating economic activity in the Roman Republic around 450 BCE. These laws refer to assets owned jus in rem (right to a thing) and jus in personam (rights against a person) [34].

Jus in rem is the exclusive ownership (dominium) of a person or business over private property (res). The three components of jus in rem are: (1) the right to use the good (usus); the right to what it produces (fructus); and the right to sell or give away the good (abusus). Notably, the usus, fructus, and abusus for the same asset may belong to different persons. For example, if Amazon leases a car, the fructus and abusus of the car still belong to Amazon; however, they lose the usus, which now belongs to the leasee. While the concepts of usus, fructus, and abusus are intrinsic to property rights, they are also useful tools to delineate the characteristics of claims and obligations from jus in personam. [35]

Jus in personam is an explicit agreement between specific parties, in which one party is obliged to do or perform some specific duties on behalf of the other. Accordingly, a real contract (obligatio re contracta) requires that something should be transferred from one party to the other and that the obligation arising should be for the return of that thing (e.g., loans of money, loans of goods, deposits, and pledges). In contrast, consensual contracts (contractus consensus) needed no transaction and were formed solely by consent between two parties. Though only four such consensual contracts are known to the law, they were the most important in ordinary life and have had a profound impact upon the subsequent development of law across Western Europe. The four agreements grouped together in the justinianic scheme as consensual contracts are: (1) sale/purchase (emptio ven ditio); (2) lease (locatio conductio); (3) partnership (societas); and (4) agency (mandatum) [34][36]. In addition to the direct link to Roman contract law, our asset-rights dimension is also consistent with the extant literature on property rights [37], as well as the transaction cost approach to contracting [38].

While the consensual contracts address the type of digital rights offered (i.e., how value is appropriated), they do not specify the type of digital assets involved (i.e., what digital offering assets have been created for appropriation). The latter draws on the Roman notion of res (things) and entails a differentiation between tangible assets (res corporales) and intangible assets (res incorporales). In addition to the direct link to Roman contract law, our asset-type dimension is also consistent with the extant literature describing the transformation from a physical to a digital economy [4]. However, while the extant literature focuses on differences among asset types and their association with organizational boundaries, the current paper only considers the interaction between asset rights and asset types.

Consequently, drawing upon the doctrinal foundation of consensual contracts and the Roman law of 'things,' the conceptual typology presented in this paper focuses on the two dimensions of (1) digital rights offered and (2) digital assets involved. These two dimensions lead to eight digital offering archetypes, which we illustrate through the diverse Amazon portfolio of digital offerings.

\section{Conceptual Typology}

\subsection{Dimension 1: Digital Rights Offered}

The primary dimension of the typology of digital offerings delineates the digital rights offered through four contractual modes (i.e., how value is appropriated). Towards this end, we consider four types of asset rights.

First, digital selling draws upon the Roman logic of sales/purchase contracts (emptio ven ditio), where the ownership (dominium) of the asset (res) is transferred in full or through a combination of the usus, fructus, and abusus.

Second, digital leasing draws upon the logic of leasing contracts (locatio conductio), where mutual 
consent is established between two parties, with one party agreeing to transfer the usus and fructus of the res to the other for a period of time.

Third, digital partnering draws upon the Roman logic of partnership contracts (societas), where a collective contract enables participants to contribute and use pooled assets for agreed-upon purposes towards shared profits.

Fourth, digital agencing draws upon the Roman logic of agency (mandatum), where mutual consent is reached between two parties, with one party asking the other party to perform a specific act on behalf of the former and the counterparty agreeing to do so.

\subsection{Dimension 2: Digital Assets Involved}

The second dimension of the typology of digital offerings delineates the type of assets involved (i.e., what digital offerings have been created for appropriation). We differentiate between two digital asset types.

First, tangible digital assets draw upon the Roman logic of tangible assets (res corporales). While this concept refers to purely physical or tangible objects, in the case of digital offering such assets will be considered only when bundled with intangible assets (res incorporales) [34]. Specifically, bundled digital assets imply that software cannot be separated from its inherent physical components and includes digitized interactive platforms through which actors (often consumers and their associated social networks) are engaged in interacting with organizing actors (often firms and their associated organizational ecosystem) in joint spaces of interactive system-environments (e.g., Amazon Kindle e-readers, Amazon Fire tablets, Amazon Fire TV, and Amazon Echo and Alexa) [12].

Secondly, intangible digital assets draw upon the Roman logic of intangible assets (res incorporales), which are abstract in nature.

\subsection{Direct vs. Indirect Transactions}

Building upon the logic that perhaps the most fundamental aspect of what a business offers is the kind of legal right conferred to the buyer upon the completion of the exchange (under the principles of contract law) [39], the eight digital offering archetypes are grouped into overarching categories of direct and indirect transactions. In a direct transaction, the offering is exchanged directly between the producer and the consumer (i.e., sellers transacting what they have produced), whereas an indirect transaction implies mediation, as the exchange of the offering is moved through other channels in order to reach its consumer (i.e., sellers transacting what others have produced). Of course, as illustrated in the case of Amazon, there can be overlaps between the two, as Amazon transacts both the company's private label brands and third-party brands side by side in the same e-commerce marketplace. Nevertheless, the (in)direct transaction distinction is considered meaningful as a guiding principle toward a greater understanding of the different digital offering types.

Furthermore, while the three components of usus, fructus and abusus are central to the first two types of rights described (1) emptio ven ditio and (2) locatio conductio (both grouped as direct transactions), they have little to do with the two last types, (3) societas and (4) mandatum (both grouped as indirect transactions). As such, this (in)direct transactional differentiation, while not directly highlighted in Roman law, is supported by the underlying components of jus in rem (right to a thing).

\section{Table 1. The typology of digital offerings}

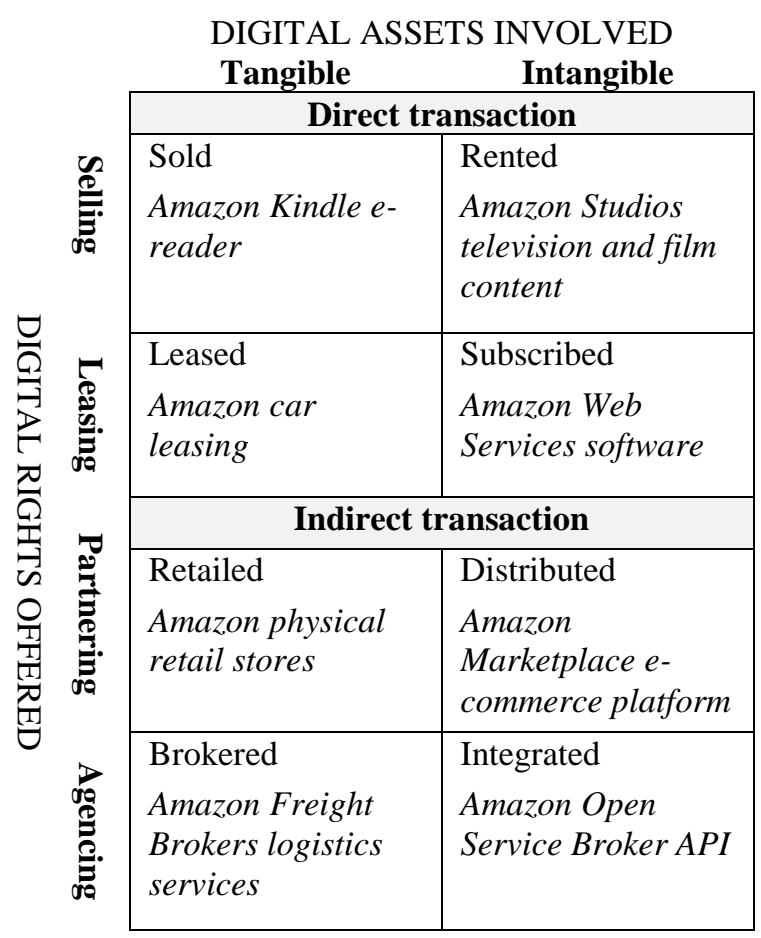

\subsection{The Eight Digital Offering Archetypes}

While some companies focus on the specialized delivery of a single digital offering and thereby identify with one digital offering archetype (e.g., PayPal), others present a range of digital offerings and consequently find representation across several archetypes. To illustrate this point, the typology of digital offerings draws its (non-exhaustive list of) empirical illustrations from the company with the 
arguably most diverse set of digital offerings in the world - Amazon [40].

As table 1 shows, each of the digital rights can be bridged with each of the digital assets involved, resulting in eight detailed digital offering archetypes. Definitions and examples of these archetypes are as follows:

Sold: Digital selling relates to bundled digital goods offered to buyers; for example, Amazon Kindle is a series of e-readers enabling users to browse, buy, download, and read e-books, newspapers, and magazines via the Kindle Store.

Rented: Digital renting relates to intangible digital goods offered to buyers; for example, Amazon Studios creates and produces original films and television series for a global audience.

Leased: Digital leasing relates to temporary use of bundled assets; for example, Amazon car leasing allows customers to lease vehicles through the new online 'Motors' store from a number of brands with free delivery to their door.

Subscribed: Digital subscription relates to temporary use of intangible assets; for example, Amazon Web Services (AWS) is a comprehensive, evolving cloud computing platform including packaged software as a service (SaaS).

Retailed: Digital retailing relates to partnerships wherein distribution is handled through in-store experiences bundled with online intelligence; for example, Amazon physical retail stores is a chain of data-driven department stores selling physical products to in-person shoppers.

Distributed: Digital distribution relates to partnerships where distribution is handled through intangible online marketplaces; for example, Amazon Marketplace e-commerce platform enables third-party sellers to sell new or used goods through a fixed-price online platform alongside Amazon's regular offerings.

Brokered: Digital brokering relates to sales or exchanges by matching potential buyers and sellers against a fee or commission from the buyer, the seller, or both in regard to data-driven bundled digital offerings; for example, Amazon Freight Brokers logistics services is a shipping solution for Amazon vendors and sellers, which automates appointment scheduling and allows certain products to be buyable in transit.

Integrated: Digital integration relates to sales or exchange by matching potential buyers and sellers against a fee or commission from the buyer, the seller, or both in regard to intangible digital offerings; for example, Amazon Open Service Broker API allows developers using application platforms to provision and expose native AWS services from within application platform interfaces.

\section{Discussion}

\subsection{Validity}

While there is no single right way to distinguish different types of digital offerings, some typologies are certainly more coherent than others. In developing the typology of digital offerings, we were guided by the following four criteria [39], [41].

First, the typology is intuitively sensible in that it captures the common intuitive essence of digital offering archetypes by grouping similar digital outputs based upon similarities in their value appropriation (digital rights offered vs. digital assets involved). Furthermore, the names of the different categories are self-explanatory (sold; rented; leased, subscribed; retailed; distributed; brokered; integrated).

Second, the typology is collective, exhaustive, and mutually exclusive in that it provides a systematic way of classifying all digital offerings, not just 'intangible' offerings or any other restricted subset of digital offerings (e.g., going beyond purely digital offerings to include both bundled and digitally augmented offerings). However, while the digital offering archetypes are mutually exclusive, they are not always independent. Rather, a digital object might potentially span across several digital offering archetypes at once, as these archetypes can function as bearers of nonmaterial objects (e.g., Kindle e-reader) [42][43], thereby spanning both the tangible and intangible asset types. Furthermore, digital offerings may become bundled, not only at the asset level but also extending to the digital rights offered. In the case of Amazon, this can be illustrated through their virtual product bundles, which let brand owners create virtual bundles made up of two to five complementary Amazon Standard Identification Numbers (ASIN), which are purchased together from a single detail page. Essentially, the typology of Digital Offerings thereby provides a modular toolkit to disassemble the building blocks of digital offering bundles, while also providing a vocabulary for the emerging phenomenon of digital offerings.

Third, the typology constructs validity in the sense that it defines systematic rules for categorizing the digital offering(s) of a given company in a way that does not depend on highly subjective judgment (e.g., description and exemplification of key concepts).

Fourth, the typology is conceptually elegant, as it uses as few simple concepts as possible (i.e., four rights-related concepts and two asset-related concepts). 
Combined, these four validity-oriented criteria ensure the logical coherence of the typology of digital offerings.

\subsection{Physical vs. Digital Terminology}

Extant literature shows a tendency to treat digital services, digital products, and digital offerings as relatively synonymous concepts. The notable exception is Micken et al. [7], who offers a view of digital offering variations located along a continuum anchored at one end by digital products and the other by digital services. Thereby, all services/products are seen as offerings, but not all offerings are seen as neither services nor products (i.e., offerings is an umbrella term).

The difficulty in drawing boundaries between digital products and digital services is not surprising in current times when different digital offerings of all sorts are permeating business in new ways every day. Historically, the conceptual demarcation between products and services arose because of the concrete nature of products, which had a presence in time and space, as opposed to services, which, with typical British humor, were characterized as "products of economic activity that you can't drop on your foot." [44]. The product vs. service distinction was reflected in Roman contract law as the difference between sale/purchase (emptio ven dito) vs. lease (locatio conductio). The latter category covered the hiring or leasing of things as well as contracts of employment in the form of either a hired service or a contract for work to be done [34].

As economies move into the digital realm, the distinction between digital products and digital services is gradually breaking down, and definitions such as the 'foot-drop test' lose their usefulness [24]. For instance, if we think of an e-book in the Amazon Kindle Store as a product, then how do we categorize the digital notes we have made in the e-book? Or the ability to share these e-book notes with our social network by linking our Kindle to our Facebook or Twitter account? Are these capabilities a part of the ebook product itself or add-on services? Similarly, is Amazon map tracking categorized as a digital product or a digital service? These examples illustrate the increasing meaninglessness of attempting to transfer the terminology of the physical world to the digital realm.

Instead, as argued by Normann and Ramirez [3] three decades ago, the focal point should be that an offering is a unique offering whether it refers to a product or a service. The same logic still applies to digital offerings, though amplified by their unique characteristics. Specifically, digital offerings can either be perpetually embodied in information and communication technologies (e.g., digitized interactive platforms such as Amazon Echo and Alexa) or ephemerally enabled by information and communication technologies (e.g., digital content such as original Amazon television and film productions). Accordingly, digital services and products are characterized by a dialectical interaction. They are different but enable and constrain each other as part of the offering [23].

In essence, the attempt to distinguish digital products from digital services is becoming increasingly irrelevant. Rather, we advocate that digital service-product mixes are collapsed into digital offerings, and consequently value conceptualizations shift from the appropriation of value through exchange (products) and use (services) towards the appropriation of value through interactions (offerings). Instead of accounting for offering variations through a continuum that clings to the service vs. product terminology of the physical world [7], the typology of digital offerings aims to categorize mutually exclusive digital offering archetypes based on the inherent merits of digital offerings. In other words, we embrace digital terminology and categorization rather than attempting to transfer the terminology of the physical world to the digital realm.

\subsection{The Front-end of Technology}

The typology of digital offerings delivers an ambitious categorization of the digital outputs of companies by distinguishing between the type of digital rights offered and the digital assets involved. While the study of offerings historically has been focused within the domains of marketing and strategic management, digital offerings draw on the research on digital components, which are nested within the domain of IS. Within the IS domain, the digital innovation literature mainly focuses on the design of IT to enable innovation but tends only to regard that which is actually being innovated - that is, the digital output of firms (i.e., their digital offerings) - through its focus on platforms as multisided markets [45][46] and platform business models [47].

Specifically, the IS discipline was initially focused on systems development and the creation of IT artifacts. However, with time, the IS community has shifted its original focus on the front-end work process and methods of system development towards a growing interest in the back-end of technology, looking at the underlying systems and platforms, as well as the infrastructure and its impact. Thereby, with the notable exception of platform literature, where digital offerings are indeed considered a salient area of 
concern, the output of what is being created by firms and exchanged with buyers (under the principles of contract law) remains under-researched within the IS domain.

Correspondingly, this paper broadens the scope of IS research by proposing a broader perspective on the front-end of technology compared to those that currently characterize the platform literature. Essentially, the paper thereby enables the IS discipline to further engage in research on value appropriation by understanding the legal foundation of the interaction between contractual parties.

\subsection{Links to Global Scaling}

Scalability is a key property of digital offerings. However, there are likely to be variations in the extent of offering scalability across the eight digital offering archetypes. For instance, digital artifacts with an intangible ephemeral embodiment (such as software code) are purportedly much more easily globally enacted than digital artifacts with a tangible perpetual embodiment (e.g., Amazon Kindle e-readers, Fire tablets, Fire TV, or Echo and Alexa) [48][23]. Similarly, upstream digital rights can be linked to different types of entry modes in global markets. Specifically, the Roman contract law understood partnership (societas) as a collective contract in which participants contributed and used pooled assets for agreed-upon purposes, subjecting the resulting profits to common ownership (communio). From a global scaling perspective, it can be exemplified through contractual modes of partnering, such as equity joint ventures. These are typically characterized by a high degree of control, global integration and strategic flexibility as well as high risk, returns, and resource commitment [49]. In contrast, agency (mandatum) arose from mutual consent between two parties, with one party asking the other to perform some specific act on behalf of the former and the counterparty agreeing to do so. From a global scaling perspective, it can be exemplified through export modes such as sales agents. These are typically characterized by a low degree of control, global integration and strategic flexibility as well as low risk, returns, and resource commitment [49].

Further unfolding the link between the digital offering archetypes and global scaling constitutes an obvious avenue for future research. Specifically, a processual understanding of individualized masscustomization of digital offerings would make a valuable contribution to the IS domain.

\section{Conclusion}

Few concepts in business today are as widely adopted, and as seldom systematically studied, as digital offerings. In this paper, we have taken a first step toward the systematic study of digital offerings by categorizing the digital outputs of companies in a reliable and practical typology. The typology builds on the underlying logic that perhaps the most fundamental aspect of what a business offers is the kind of legal rights conferred to the buyer upon the completion of the exchange.

Correspondingly, building on the strength of Roman law, we set out to classify digital offering archetypes by drawing on the legal code of contract rights to identify the core building blocks of digital rights and digital assets, as institutionalized into the legal context. Specifically, we draw upon contract law to conceptualize the different types of asset rights involved in transferring the ownership of digital offerings asset types.

Thereby, the typology of digital offerings draws on contract law to establish its dimensions. Specifically, the first dimension of the typology equals the type of digital rights offered - that is, how value is appropriated. Toward this end, we consider four types of digital rights: (1) selling, (2) leasing, (3) partnering, and (4) agencing. The second dimension is the type of digital assets involved - that is, what digital offering assets have been created for appropriation. We distinguish between two digital asset types: (1) tangible (only considered as bundled digital assets) and (2) intangible. Together, these two dimensions lead to eight digital offering archetypes being identified and illustrated through the diverse Amazon portfolio of digital offerings.

Ultimately, by accounting for digital offering variations based on the inherent merits of digital offerings, rather than drawing on the common service vs. product logic, we embrace digital terminology rather than attempting to transfer the terminology of the physical world to the digital realm.

\section{References}

[1] J. W. Ross, C. M. Beath, and M. Mocker, "Creating Digital Offerings Customers Will Buy: Find the Sweet Spot between what Technologies can Deliver and what your Customers Need," MIT Sloan Manag. Rev., 2019, pp. 2-7.

[2] Ross, J. W., C. M. Beath, and M. Mocker, Designed for Digital: How to Architect your Business for Sustained Success. MIT Press, Cambridge, Massachusetts Institute of Technology, 2019. 
[3] R. Normann and R. Ramirez, "A Theory of the Offering: Toward a Neo-industrial Business Strategy," in Strategy, Organisation Design, and Human Resource Management, C. C. Snow, Ed. J.A.I. Press, 1989, pp. 111-128.

[4] R. L. Baskerville, M. D. Myers, and Y. Yoo, "Digital first: The ontological reversal and new challenges for information systems research," MIS Q. Manag. Inf.

Syst., vol. 44, no. 2, 2020, pp. 509-523, doi: 10.25300/MISQ/2020/14418.

[5] K. Lewin, "The Research Centre for Group Dynamics at Massachusetts Institute of Technology," Sociometry, vol. 8, 1945, pp. 126-135.

[6] S. Gregor, "The Nature of Theory in Information Systems," MIS Q., vol. 30, no. 3, 2006, pp. 611-642.

[7] K. S. Micken, S. D. Roberts, and J. D. Oliver, "The Digital Continuum: the Influence of Ownership, Access, Control, and Cocreation on Digital Offerings," AMS Rev., vol. 10, 2020, pp. 98-115, doi: 10.1007/s13162-019-00149-5.

[8] Normann, R., Management for Growth, John Wiley \& Sons, Chichester, 1977.

[9] Gustafsson, A. and M. D. Johnson, Competing in a Service Economy: How to Create a Competitive Advantage through Service Development and Innovation. University of Michigan Business School Management Series, Chichester, 2003.

[10] W. J. Orlikowski and S. C. Lacono, "Desperately Seeking the 'IT' in IT Research: A Call to Theorizing the IT Artifact,” Inf. Syst. Res., vol. 12, no. 2, 2001, pp. 121-134.

[11] C. Grönroos and P. Voima, "Critical Service Logic: Making Sense of Value Creation and Co-creation," J. Acad. Mark. Sci., vol. 41, no. 2, 2013, pp. 133-150, doi: 10.1007/s11747-012-0308-3.

[12] V. Ramaswamy and K. Ozcan, "Offerings as Digitalized Interactive Platforms: A Conceptual Framework and Implications," J. Mark., vol. 82, no. 4, 2018, pp. 19-31, doi: 10.1509/jm.15.0365.

[13] D. Ballantyne, "Dialogue and its Role in the Development of Relationship Specific Knowledge," J. Bus. Ind. Mark., vol. 19, no. 2, 2004, pp. 114-123, doi: 10.1108/08858620410523990.

[14] D. Ballantyne and R. J. Varey, "Creating Value-inUse through Marketing Interaction: The Exchange Logic of Relating, Communicating and Knowing," Mark. Theory, vol. 6, no. 3, 2006, pp. 335-348, doi: $10.1177 / 1470593106066795$.

[15] S. Wikström, "Value Creation by CompanyConsumer Interaction," J. Mark. Manag., vol. 12, no. 5, 1996, pp. 359-374, doi: 10.1080/0267257X.1996.9964422.

[16] R. Reisman and M. Bertini, "A Novel Architecture to Monetize Digital Offerings," J. Revenue Pricing Manag., vol. 17, no. 6, 2018, pp. 453-458, doi: 10.1057/s41272-018-0143-3.

[17] A. Payne, P. Frow, and A. Eggert, "The Customer Value Proposition: Evolution, Development, and Application in Marketing," J. Acad. Mark. Sci., vol. 45, no. 4, 2017, pp. 467-489, doi: 10.1007/s11747- 017-0523-z.

[18] C. Zott, R. Amit, and L. Massa, "The Business Model: Recent Developments and Future Research," J. Manage., vol. 37, no. 4, 2011, pp. 1019-1042, doi: $10.1177 / 0149206311406265$.

[19] Lusch, R. F., and S. L. Vargo, "Service-Dominant Logic: As a Foundation for a General Theory," in The Service Dominant Logic of Marketing, R. F. Lusch and S. L. Vargo, Eds. M. E. Sharpe, Armonk, 2006, pp. 406-420.

[20] Y. Truong, G. Simmons, and M. J. Palmer, "Reciprocal Value Propositions in Practice: Constraints in Digital Markets," Ind. Mark. Manag., vol. 41, no. 1, 2012, pp. 197-206, doi: 10.1016/j.indmarman.2011.11.007.

[21] L. G. Mattsson, "Systems Selling as a Strategy on Industrial Markets," Ind. Mark. Manag., vol. 3, no. 2, 1973, pp. 107-120.

[22] F. Nordin and C. Kowalkowski, "Solutions Offerings: A Critical Review and Reconceptualisation," J. Serv. Manag., vol. 21, no. 4, 2010, pp. 441-459, doi: $10.1108 / 09564231011066105$.

[23] J. Lehmann and J. Recker, "Offerings that are 'Everin-the-Making': Post-Launch Continuous Digital Innovation in Late-Stage Entrepreneurial Ventures," in Fortieth International Conference on Information Systems, 2019, pp. 1-17.

[24] S. D. Roberts, K. S. Micken, S. D. Roberts, and K. S. Micken, "Marketing Digital Offerings Is Different: Strategies for Teaching About Digital Offerings in the Marketing Classroom," J. Educ. Bus., vol. 2323, no. 90,2015 , pp. $96-102$, doi: 10.1080/08832323.2014.988200.

[25] J. Kallinikos, A. Aaltonen, and A. Marton, "The Ambivalent Ontology of Digital Artifacts," MIS Q., vol. 37, no. 2, 2013, pp. 357-370, doi: 10.25300/MISQ/2013/37.2.02.

[26] Y. Yoo, "Computing in Everyday Life: A Call for Research on Experiential Computing," MIS Q., vol. 34, no. 4, 2010, pp. 669-688, doi: 10.2307/20721425

[27] Y. Yoo, O. Henfridsson, and K. Lyytinen, "Research Commentary - The new organizing logic of digital innovation: An agenda for information systems research," Inf. Syst. Res., vol. 21, no. 4, 2010, pp. 724-735, doi: 10.1287/isre.1100.0322.

[28] S. L. Jarvenpaa and W. Standaert, "Digital Probes as Opening Possibilities of Generativity," J. Assoc. Inf. Syst., vol. 19, no. 10, 2018, pp. 982-1000, doi: 10.17705/1jais.00516.

[29] T. Tuunanen, T. Böhmann, and O. Henfridsson, "Introduction to the Minitrack on Digital Services and The Digitalization of Services," Proc. 52nd Hawaii Int. Conf. Syst. Sci., 2019, pp. 1383-1385, doi: 10.24251/hicss.2019.168.

[30] V. Ramaswamy, "Leading the Experience Ecosystem Revolution: Innovating Offerings as Interactive Platforms," Stategy Leadersh., vol. 48, no. 3, 2020, pp. 3-9, doi: 10.1108/SL-01-2020-0014.

[31] R. C. Nickerson, U. Varshney, and J. Muntermann, "A Method for Taxonomy Development and its 
Application in Information Systems," Eur. J. Inf. Syst., vol. 22, no. 3, 2013, pp. 336-359, doi: 10.1057/ejis.2012.26.

[32] A. Rizk, B. Bergvall-Kåreborn, and A. Elragal, "Towards a Taxonomy for Data-Driven Digital Services," Proc. 51st Hawaii Int. Conf. Syst. Sci., 2018, pp. 1076-1085, doi: 10.24251/hicss.2018.135.

[33] K. L. Hui and P. Y. K. Chau, "Classifying Digital Products," Commun. ACM, vol. 45, no. 6, 2002, pp. 73-79, doi: 10.1145/508448.508451.

[34] K. Tsujimura and M. Tsujimura, "Roman Law in the National Accounting Perspective: Usus, Fructus and Abusus," Stat. J. IAOS, vol. 1, 2021, pp. 1-16, doi: 10.3233/SJI-210810.

[35] Salanie, B., The Economics of Contracts: A Primer, The MIT Press, Cambridge, MA, 1998.

[36] P. J. Du Plessis, "The Roman Concept of Lex Contractus," Rom. Leg. Tradit., vol. 3, 2006, pp. 7994.

[37] S. J. Grossman and O. D. Hart, "The Costs and Benefits of Ownership: A Theory of Vertical and Lateral Integration," J. Polit. Econ., vol. 94, no. 4, 1986, pp. 691-719, doi: 10.1086/261404.

[38] O. E. Williamson, "Markets and hierarchies, some elementary considerations," Am. Econ. Rev., vol. 63, no. 2, 1973, pp. 316-325.

[39] T. W. Malone et al., "Do Some Business Models Perform Better than Others?," MIT Working Paper 4615-06, 2006, pp. 1-34. doi: 10.2139/ssrn.920667.

[40] "Amazon." https://www.amazon.com/. Accessed: 11 December 2020.

[41] Scott, W. R., Organizations: Rational, Natural, and Open Systems, Prentice Hall, Englewood Cliffs, NJ, 1981.
[42] P. Faulkner and J. Runde, "Theorizing the Digital Object," MIS Q., vol. 43, no. 4, 2019, pp. 1278-1302, doi: 10.25300/MISQ/2019/13136.

[43] P. Faulkner and J. Runde, "Technological Objects, Social Positions, and the Transformational Model of Social Activity," MIS Q., vol. 37, no. 3, 2013, pp. 803-818, Available: https://www.jstor.org/stable/43826001.

[44] The Economist, "Service Definition," Essential Economics, 2021. https://www.economist.com/economics-a-toz/s\#node-21529672. Accessed: 05.03.2021.

[45] Evans, D. S. and R. Schmalensee, Matchmakers: The New Economics of Multisided Platforms, Harvard Business Review Press, Boston, Massachusetts, 2016.

[46] G. G. Parker, M. W. Van Alstyne, and S. P. Choudary, Platform Revolution: How Networked Markets are Transforming the Economy - and How to Make Them Work For You. W. W. Norton \& Company Limited, 2016.

[47] K. Täuscher and S. M. Laudien, "Understanding Platform Business Models: A Mixed Methods Study of Marketplaces," Eur. Manag. J., vol. 36, no. 3, 2018, pp. 319-329, doi: 10.1016/j.emj.2017.06.005.

[48] F. Von Briel, J. Recker, and P. Davidsson, "Not all Digital Venture Ideas are Created Equal: Implications for Venture Creation Processes," J. Strateg. Inf. Syst., vol. 27, no. 4, 2018, pp. 278-295, doi: 10.1016/j.jsis.2018.06.002.

[49] C. W. L. Hill, P. Hwang, and W. C. Kim, “An Eclectic Theory of the Choice of International Entry Mode," Strateg. Manag. J., vol. 11, no. 2, 1990, pp. 117-128, doi: 10.1002/smj.4250110204. 